Research Journal of Applied Sciences 6 (4): 223-231, 2011

ISSN: $1815-932 \mathrm{X}$

(C) Medwell Journals, 2011

\title{
Nominal Group Technique and Participation Applied to Water Management for Agricultural Uses
}

\author{
Estrella Bernal \\ Department of Management, EUEEZ University of Zaragoza, \\ C/Maria De Luna S/n. 50018 Zaragoza, Spain
}

\begin{abstract}
This study seeks to present development alternatives for a rural area in Spain within parameters of sustainability that place the option of irrigation as one among several that are possible including an institutional process of public participation and using the Nominal Group Technique as a qualitative tool for participation. These various options are delineated by the social groups involved in the decision in question. We shall expound the participatory process engaged in by the main actors involved in the problem of irrigation in the particular territory. Their visions (alternatives) of future development as well as their criteria for assessing these alternatives in the socio-economic and environmental realms are brought together and ordered. This results in a ranking of preferences with respect to the various alternatives that places irrigation in a much more marginal role than is attributed to it by certain sectors of Spanish agricultural politics, a role that is merely complementary to other options that play an essential part in development.
\end{abstract}

Key words: Sustainability, Monegros, irrigation, territorial development, participation, multi-criteria decision, scenarios, consciousness development

\section{INTRODUCTION}

The background to the participatory process: Located in the provinces of Zaragoza and Huesca (Spain), Monegros is an area that tends to be described as a semi-desert both in natural and demographic terms. For this reason, irrigation has historically been presented by the political classes as virtually the only alternative for the sustainable development and organization of the area.

To study alternatives in territorial development that are socially accepted and fall within environmentally sustainable parameters however is to confront the problem of sustainability as a multi-criteria decisionmaking process (Munda, 1997, 2004) that must be public and based on scientific information and in which the environmental, social and economic pillars are taken into account. Within this decision-making process, the option of irrigation can be assessed together with other development alternatives with the aim of defining one of these alternatives as the most desirable, bearing in mind these three aspects of sustainability. In this way, we dispense with the reductionistic vision of development associated solely with irrigation, opening the perspective up to become more inclusive of the possibilities offered by the area and its population.

The present study develops the results of the participatory processes in question in an analysis of long-term models of development for Monegros within parameters of sustainability. The objective is to place the option of irrigation as one among various other possibilities for developing the area, providing a reference based on participatory processes specifying the weight given socially to irrigation for territorial development. Accordingly, the participatory process must be understood within the theoretical framework of the issue of local-level sustainable development, confronting both its biophysical dimension and its human (socio-economic) dimension. This thus involves asking questions such as: What are the visions of future development harboured by the social agents? How will these visions influence the development of the area? This influence is doubtless subject to the randomness and evolution of the social values at stake. As such, it introduces a degree of structural uncertainty (Van Asselt, 2000) into the question of territorial sustainability that cannot be resolved with more or better empirical observations, since there is no way of predicting this social randomness: in other words, it is an irreducible uncertainty (Van Asselt and Rotmans, 2002). Nonetheless, participation is in itself a methodology for dealing with such uncertainty, for it introduces into the decision-making system the existing information on these social values and visions of the future and is not strictly defined by the underlying knowledge and values of analysts and/or decisionmakers. For this reason, the developmental options being evaluated from an economic, social and environmental 
point of view must be delineated by the social groups involved in the decisions that affect the development of the area with a view to complementing the scientific knowledge of the system (which is subject to structural uncertainty) and defining alternatives and criteria for decision-making.

It should be pointed out that there are two types of information that will provide a context for the contents of the participatory process in question: first, given that posing the problem of sustainability involves taking its three pillars into account, it is necessary to consider the biophysical dimension which fundamentally comprises technical information for social agents and analysts and to incorporate it in the decision-making process. A system of geographical information is very useful for analysing the basic territorial variables that determine sustainability. In the case of Monegros, these variables are the types of soil, limiting agricultural factors, salinity, biodiversity and interactions with existing and projected irrigation systems.

Secondly, a historical-institutional analysis (in accordance with the scenario methodology of Gallopin which identifies the evolution of the socio-economic system of Monegros over the past century and its relation with the environmental determinants for the sustainable development of the area, provides us with another source of highly valuable information to be introduced into the participatory process so it can be designed as required. This sort of analysis makes it possible to identify six basic socio-economic models of agricultural production in the area as well as the groups of interest or main social actors that are involved in the problem.

Through these analyses of the basic and socio-economic territorial variables, we identify three municipalities representative of the six production models for dry farming and irrigation that exist in Monegros: Sarinena, Lecinena and Bujaraloz. It is from these municipalities that local representatives will be chosen to take part in the participatory process even though as will be explained in the study there will also be participants from outside the area.

\section{MATETRIALS AND METHODS}

There numerous methodologies used in social participation to deal with complex environmental and social problems (Karakosta et al., 2010). In this particular case, we have find appropriated two techniques of qualitative research are carried the participatory process out: in-depth interviews (Rist et al., 2003) and focal groups. Incorporating the sources of structural uncertainty due to social factors requires adequate time for reflection, levels of information and processes of discussion to construct knowledge that is relevant to policies. This is something that is very difficult to achieve by means of codified questionnaires but that is provided by focal groups. Moreover, this type of experience will make it possible to discuss the final objectives of the evaluation in terms of the criteria defined, their validity and relevance. Likewise, we opt for the technique of life-histories because according to Delgado, Rist et al. (2003) and Rist (2004) the dynamics of different forms of knowledge plays an essential role in revitalizing local knowledge. This method also gives interviewees the greatest possible freedom in expressing their opinions with the interviewer only making comments in order to guide the course of the discussion, motivate reflection and draw contrasts with different opinions. Accordingly, both life-histories and focal groups as methods prove to be optimal for grasping the diversity of values, the variability of behaviour and the social randomness that are fundamental sources of structural uncertainty.

\section{Preliminary interviews in order to become acquainted with the area and the system:}

- With a view to complementing the information about the system obtained from historical data and institutional analyses, a series of 12 in depth interviews were carried out over a period of 3 years with farmers from the study area corresponding to the various production systems identified. The hermeneutic method of life-histories was followed in accordance with Rist et al. (2003).

- The interviews enabled us to obtain information about representative figures from the groups of interest (main actors) identified in the historical-institutional analysis and to get in contact with them in order to establish the focal groups

- In the 4th year, four more in depth interviews were carried out, this time with specialists and politicians

First phase of the focal groups: Three focal groups were organized using the Nominal Group Technique (NGT) (Delbecq et al., 1975). The results from the preliminary interviews, together with the information about the system acquired through the analysis of territorial variables and the historical-institutional analysis were incorporated into the participatory process via this first session of focal groups. The idea was for them to be discussed, modified and spelt out in more detail in the course of the process, making it clear that all these results were subject to contrast and criticism. This incorporation took the form of a preliminary sketch of the region's needs and expectations which was furnished in a dossier which also included a brief description of the research 
undertaken on the development of Monegros. Together with notice of the first session of focal groups, the dossier was sent out 3 weeks before the meeting.

Three focal groups were formed in which there were representatives of each of the actors identified, according to the following criteria:

- Focal group held in Lecinena, representing the dry area of Monegros. All the participants were from the municipality

- Focal group from Sarinena and Bujaraloz, representing the various types of irrigation-gravity, pressure and huerta vieja or traditional irrigation as well as the specific condition of the settlement village. The participants of this group were mainly from these towns but there were also participants from other nearby municipalities. The group also included representatives from ecological groups, it being considered that their presence might enhance the debate

- A third group was formed consisting of specialists and holders of public office. This group convened in Zaragoza as this was more accessible for most of those concerned

The choice of the representatives in each group was made on the basis of personal contacts with various informants involved in the distinct organizations, associations and municipal institutions and also consists of enterprising business people with numerous contacts in the social and institutional fields. Accordingly, the representatives eventually invited had shown themselves to be dynamic figures within their respective fields, people who interacted in an intense and wide-ranging way with various social bodies and were aware of the perceptions of these social bodies.

The aim was that the people taking part in the groups should be equipped with broad and good-quality information as regards the field in question based on their own experience.

All the main actors were represented in the three groups except for those not belonging to the region but identified in the historical-institutional analysis as influential in the decision-making process on development in Monegros. These are the Hydrographic Confederation of the Ebro (Confederacion Hidrografica del Ebro, CHE), the Coalition of People Affected by Large Dams and Aqueducts (Colectivo de Afectados por los Grandes Embalses y Trasvases, COAGRET) and the hydroelectric power stations. These actors decided not to take part in the focal groups for a variety of reasons either political or social, even though they were given the option of participating. The perceptions of these actors were gathered by means of three in depth interviews, one with a member of COAGRET and town councillor of Huesca and two more with two specialists from the $\mathrm{CHE}$, each with a different level of responsibility and knowledge as regards the problem of irrigation in Monegros. Their ideas concerning both development and assessment criteria have been included in the corresponding tables for the group of specialists. We proceeded in this way because the interviews hardly add any concrete ideas on top of those that already emerged from the focal groups. What the interviews do provide however is a clear confrontation of points of view as regards the ideas of development, even though the underlying interests are only explicit in the case of COAGRET. As for the hydroelectric power stations, it should be pointed out that we were only attended by the customer attention department of Electricas Reunidas de Zaragoza (ERZ) and after consulting ERZ internally, we were not passed to any higher level of management as they sayed that they had no involvement in a decision-making process regarding the development of Monegros. Nor did they provide the option of an in depth interview. However, we understand from the information obtained in the historical-institutional analysis that the option favoured by this actor is that of irrigation (since the projected dams which will also have hydroelectric uses supply enough water for such irrigation systems) and this option is already represented through the ideas of other agents.

\section{Development of the nominal group technique in the focal} groups: Given the objective of obtaining information that is qualitatively relevant for ascertaining knowledge, beliefs and values, the aim is not to bring about a confrontation of positions but to create a list of ideas on the development of Monegros based on the consensus of the whole group and reflecting the perceptions and knowledge that exist within the group relating to the problem in question. The technique fosters the gathering of a broad range of ideas from each of the participants, without the criteria of any one person being imposed on anyone else and giving a chance for all the participants first to reflect and then to express the ideas that have emerged from reflection. In order to foster such reflection, the participants were provided with the above-mentioned information dossier when they were sent notice of the meeting of the focal group. Once the meeting was underway, the following open question was posed: what ideas seem to you to be good for the future of Monegros? Participants were given $20 \mathrm{~min}$ to reflect and note any ideas that sprang to mind. These ideas were then voiced in turn; in each round each participant provided an idea 
expressed as succinctly as possible with the rounds continuing until everyone had said everything they wanted. Afterwards, a process of voting (Three items could be voted with marks of 1,3 or 5 upwards in order of preference. In the group of specialists, the range was extended to run through consecutively from $1-5$. This was because the number of participants was smaller and the aim was to obtain a list of preferred ideas that was similar in number to that produced by the other 2 groups) involving all the participants was used to draw up a list containing the most widely accepted alternatives in order of preference. This ranking will give us an idea of the points that are most relevant for the agents involved in the development process of Monegros. After drawing up this list, there was an open debate to explain and discuss any remaining doubts.

This qualitative methodology is open to criticism for its lack of statistical representativeness but the first thing to be emphasized is that the aim was not so much to achieve statistical representativeness as to guarantee that a large measure of the possible knowledge, beliefs and values might be registered thus making it possible to submit a greater amount of information to the multi-criteria analysis. Secondly if the object is to gather opinions on a topic as complex as sustainable development in Monegros, it is vital to provide enough time for reflection and suitable levels of information and discussion to be able to construct knowledge that is relevant to policies. This is very difficult to achieve using codified questionnaires which while supplying us with data that are statistically representative will not express what the people think but what the population has not had time to think.

Elaboration of the material for the first focal group Configuration of scenarios and matrix of impacts: The material making up the future visions of the main actors is arranged into four long-term future scenarios, elaborated in accordance with the methodology of archetypal development scenarios (Berkhout and Hertin, 2002; De Vries and Petersen, 2009; Eames and Skea, 2003; Raskin et al., 2002) but going beyond the cultural theory (Thompson et al., 1990) on which this methodology is based. The present study broadens the base of cultural theory using concepts from the biology of knowledge proposed by Maturana and Varela (1987). According to the model put forward by these biologists, the authentic nature of the human being and what has occasioned his evolution is his consciousness of being part of the human species and of the biosphere, thus developing relationships of equality, respect and co-operation with others and the other. Accordingly, individual wellbeing depends on the wellbeing of the group and on the good condition of the environment in which they live. In scenario construction for the participatory processes, the specific degree to which this consciousness is developed in the two fields of belonging to the human group and to the biosphere gives rise to four different future scenarios, constituting the four fundamental dimensions of change in the scenarios. Therefore, depending on this development of consciousness, we obtain four different scenarios.

Each of these four scenarios describes a possible future in accordance with four different perspectives that seek to bring together the distinct perceptions of the main actors. These four perspectives are the following:

Scenario 1 (S1) based on global responsibility, describes a Monegros in which social and environmental values predominate, social equity and the rational collective use of resources is regarded as essential to development, nature is recognized to be fragile and it is considered important to use the principle of prudence when faced with any decision that involves an environmental impact. In Scenario 2 (S2), based on technocratic management from urban centres, value is attached to the environment but this is from the perspective of urban values that see the environment as just one good among many which produces individual wellbeing and requires technical management from the centres of information and power. It is assumed that achieving individual wellbeing will result in social wellbeing. In Scenario 3 (S3), based on rural social management, the social values of the people of Monegros hold sway i.e., their feeling of community and territorial identity and their desire to protect this; social equity is defended because it is considered necessary for development. Economic development is regarded as basic to social wellbeing; nature is an instrument for achieving this, considered robust enough to withstand economic activity and technology is trusted to be able to solve in the future any environmental problem created now. In Scenario 4 (S4), based on the market as the manager, the free-market perspective predominates. According to this, the wellbeing of a society is attained if each individual pursues his individual wellbeing and nature is merely a supply of resources to be dealt with and controlled at the discretion of man and technology which is trusted to be able to solve any problem that might emerge.

Each scenario coherently follows the various ways in which the relations of cause and effect develop in each perspective, depending on how the current critical uncertainties identified in the socio-economic system of Monegros are resolved. These uncertainties are rooted in whether the evolution of social values takes a rural or an 
urban turn, the application of the CAP supports family-run businesses or not, the implementation of the framework directive on water is consistent or not with its environmental principles and how the conflict is resolved between plain and mountain as regards the construction of dams in the Pyrenees for irrigation in the plain.

The narrative of these developments provides the hypotheses regarding the objectives pursued by society in each scenario in the environmental, economic and social realms. In accordance with the context created by these social objectives, a combination of policies is formulated designed to achieve the objectives in question.

In this way, four combinations of policies for action are obtained, each one conforming to a development alternative.

To complete the configuration of the matrix of impacts (which indicates options for development and criteria for assessment), we define each of the assessment criteria onthe basis of the collection of ideas about these criteria obtained in the first session of focal groups.

Second phase of the focal groups: In this phase the following guidelines are followed which correspond to the objectives of the phase:

- Validation of the existence in society of the various perspectives proposed in each of the four scenarios

- Validation of the plausibility of the narrative itineraries

- Evaluation of the level of preference of the various development alternatives

- Validation of the criteria found to be relevant for the population

- Qualitative aggregation of criteria

- Ranking of the preferred development alternatives in accordance with the evaluation of aggregated criteria

\section{RESULTS AND DISCUSSION}

\section{First phase of the focal groups}

Configuration of the groups: One of the results of the historical-institutional analysis was the identification of the main actors or groups representing the various interests in the decision-making process pertaining to the development of Monegros.

Given that water has traditionally been perceived in the territory as a key to development, the main actors stem not only from the interior of this territory (the plain) but also from the mountains i.e., the areas affected by the dams whose possible uses would include the irrigation schemes projected in Monegros. Also incorporated as party to the decision-making activity are certain organizations and companies from an urban context, on account of the fact that their interests will be affected by the possible developmental processes in Monegros. Further agents involved include those institutions with decision-making powers over the area or over factors that might have an effect on its possible development processes. The main actors identified are the following:

\section{In the rural areas of the plain:}

- Agricultural trade unions

- Communities of grass-roots irrigators

- Comunidad General de Riegos del Alto Aragon (the community of irrigation systems of the Aragonese Highlands)

- Associations of local businessmen

- Associations of livestock farmers

- Associations of housewives

- Young people who have not severed connections with the villages as a group of particular importance in the process

In the mountains:

- Coalition of people affected by large dams and aqueducts (COAGRET)

In the city:

- Ecological groups: SEO Aragon

- Foundations: Fundacion Nueva Cultura del Agua (Foundation for a New Culture of Water)

- Scientific groups: Association of friends of the Monegros

- Hydroelectric companies

Institutional agents:

- Town councils

- Provincial government. Huesca provincial council

- Hydrographic confederation of the Ebro

- Community of Los Monegros

- Regional government of Aragon

- Political parties on a national level

- European Union: General directorate XII

From these focal groups two fundamental results were obtained: the ideas of the main actors for the development of Monegros: the perception of the needs and expectations of the area (social, environmental, political, technical and economic, etc.), their relative importance and the vision for the future of the study area as desired by the inhabitants and the main actors in the decision-making process. The ideas of the main actors with regard to the most important criteria for assessing the possible alternatives of economic development. 
These perceptions provide basic material for determining the conditions which according to the main actors would be indispensable for development to take place (for example, a clean environment, without the smell of pig purines or plastic waste in the fields). They likewise suggest the measures in terms of policies and economic initiatives that need to be taken for these conditions to be brought about (for example, the incentive of information policies on collection points for solid wastes or policies regarding the management and distribution of pig purines).

\section{Results of the rounds of participation in the NGT in the} first phase of the focal groups: As for the interviews carried out with representatives from Che and Coagret, there are contradictory arguments among the Che specialists regarding the issue of irrigation, making it difficult to understand their position unless the institution has interests they do not make explicit. The contradiction basically resides on the one hand in attaching great importance to irrigation as a factor in development while on the other hand denying this importance by recognizing that there are other factors equally or more important or that the lack of a generation to take over leaves irrigation without effect on development.

Second phase of the focal groups: Both the existence in society of the four perspectives proposed and the plausibility of the narrative itineraries with the combination of policies (developmental alternatives) proposed for each scenario were validated with the participants. It was likewise validated that the criteria proposed for evaluation included all the ideas for criteria proposed by the agents in the focal groups. The participants carried out a qualitative aggregation of these evaluation criteria, producing the following preference ranking for the four combinations of policies (or developmental alternatives): $\mathrm{S} 3>\mathrm{S} 1>\mathrm{S} 2>\mathrm{S} 4$.

The preferred scenario was number 3 where the only irrigation was 5,000 ha of social irrigation distributed in green areas in such a way that all the municipalities with acceptable land were able to take part in it with considerable backing given to family-run farms. The least preferred scenario was number 4 which proposed the development of the national irrigation plan PNR H-2008 with 26,000 ha of irrigation and without any support given to family-run farms. Scenarios 1 and 2 planned not to extend the irrigation by a single hectare. In Scenario 1, the developmental alternative involved a combination of agricultural and hydraulic policies that were both environmental and social in which irrigation played only a marginal role and the action proposed in this respect was the modernization of all the irrigation systems. Scenario 2 also proposed the modernization of irrigation systems but without the major backing given to family run businesses included in Scenario 1.

Given the great importance attributed to irrigation in Spain by political bodies and apparent public perceptions, it is interesting to highlight one of the results obtained in the focal groups.

Of all the ideas that were proposed, only $6 \%$ were related to irrigation and only $2.2 \%$ to a plan for new irrigation that does not incorporate (at least not explicitly) modernization or social criteria. Of all the ideas that were voted for $12.5 \%$ were related to irrigation and $6.25 \%$ to new irrigation that does not incorporate (at least not explicitly) modernization or social criteria. These percentages are merely descriptive of the results obtained in the groups and are not statistically representative, since as explained above the aim was not so much to achieve statistical representativeness as to ensure that a large measure of the possible knowledge, beliefs and values might be registered, thus making it possible to submit a greater amount of information to the multi-criteria analysis. Nonetheless, the painstaking and meticulous process of approaching the area and the informants in question through in-depth interviews, the implementation of a historical-institutional analysis that helped identify the main actors involved and the choice of representatives to take part in the process on the basis of the information from the previous interviews, all ensure that the results from the focal groups are high in quality and embody a broad range of the information gathered (Table 1-3).

Of the 31 participants, only three (all in the dry-farming area) voted in favour of new irrigation in accordance with the national irrigation plan PNR H-2008 (the actual expectation at the time being for 26,000 ha of new irrigation). Two participants voted in favour of the option of social irrigation systems, rationalizing only where the systems had this function and in green areas of $<2,500$ ha (one of these participants was from an irrigated area and the other from the group of specialists and politicians). Finally, one participant (also from the group of specialists and politicians) voted in favour of the modernization of irrigation systems. In other words, from a heterogeneous body of 31 people amply representative of the agricultural sector (as can be seen in the list of representatives) who contributed a total of 132 items (ideas for development), there only emerged eight items related to irrigation of which only six were voted for (the other two were put forward in the rounds of ideas but ended up not getting any votes). The total number of items voted for was 48 . It seems therefore that the 
Res. J. Applied Sci., 6 (4): 223-231, 2011

Table 1: Ideas for the development of Monegros obtained in focal group 1 (Lecinena)

\begin{tabular}{|c|c|c|}
\hline Items & Points & Votes \\
\hline Water for irrigation (new social irrigation systems, greenhouses) & 13 & 3 \\
\hline Industrial estates in the villages (to attract population) & 9 & 3 \\
\hline Extension of services: transport & 11 & 2 \\
\hline Taking advantage of proximity to Zaragoza & 10 & 2 \\
\hline Cooperation, associations and common defence of resources & 8 & 2 \\
\hline Rural tourism & 8 & 2 \\
\hline Taking advantage of the special features of the steppe, the image of Monegros and attracting people from green landscapes & 4 & 2 \\
\hline Taking advantage of the special features of the natural landscapes & 2 & 2 \\
\hline Public investment in looking after nature (environmental service as a livelihood). Active politics & 2 & 2 \\
\hline Ecological agriculture & 5 & 1 \\
\hline Schools adapted to the realities of the rural world/secondary education & 5 & 1 \\
\hline Assessed town and country planning & 3 & 1 \\
\hline Activities related to the landscape (taking advantage of the landscape) & 3 & 1 \\
\hline Facilitating accommodation (Urban planning and incentives for restoration) & 3 & 1 \\
\hline Combination of alternatives & 1 & 1 \\
\hline Agro-food industries & 1 & 1 \\
\hline Improving (widening) local roads between villages & 1 & 1 \\
\hline Coordinated work to create an element that provides the territory with a distinctive brand & 1 & 1 \\
\hline Infant education oriented towards an appreciation of local identity, environment and culture & - & 0 \\
\hline Telework/working from home (to encourage people to stay in the village) & - & 0 \\
\hline Leisure spaces for young people (to encourage them to stay) & - & 0 \\
\hline Educational spaces for city children (educational farms, etc.) & - & 0 \\
\hline Spaces for elderly people (residences) or services within the village (e.g., home help) & - & 0 \\
\hline Hunting farms & - & 0 \\
\hline Handicraft activities (food, home products, selling local confectionery outside Lecinena) & - & 0 \\
\hline Broadband communication infrastructures & - & 0 \\
\hline Museum of machinery and historical tools & - & 0 \\
\hline Getting rid of the smell of the pigs & - & 0 \\
\hline Products derived from pigs & - & 0 \\
\hline Environmental education, mountain leisure activities (rehabilitation of mountain huts), bicy cles, horses and camps & - & 0 \\
\hline Rehabilitation of paths & - & 0 \\
\hline Livestock farming in harmony with environment (goats in the mountains) & - & 0 \\
\hline Altemative crops: flowers and vineyards & - & 0 \\
\hline Historic theatre & - & 0 \\
\hline
\end{tabular}

Table 2: Ideas for the development of monegros obtained in focal group 2 (Sarinena-Bujaraloz)

\begin{tabular}{|c|c|c|}
\hline Items & Points & Votes \\
\hline Improving all communications including internet & 10 & 4 \\
\hline Detailed account of natural and human resources & 15 & 3 \\
\hline Attracting population and generating work for women & 7 & 3 \\
\hline Creation of a national park & 7 & 3 \\
\hline Concrete training plan for the special needs of the people of Monegros & 5 & 3 \\
\hline Transformation of agricultural and livestock products & 10 & 2 \\
\hline Decent urban environment (no straw ricks, no purines), accommodation & 8 & 2 \\
\hline Extensive agriculture or change to a sustainable model (ecological agriculture) & 8 & 2 \\
\hline Recovering and appreciating natural resources & 8 & 2 \\
\hline That the people of Monegros should know, appreciate and love Monegros & 5 & 1 \\
\hline Establishing ecological villages in all the settlement villages (alternative energies and cooperatives, etc.) and ascription to Agenda 21 & 5 & 1 \\
\hline Recovering traditional huerta vieja irrigation & 5 & 1 \\
\hline Promoting extensive sheep-farming linked to the landscape & 5 & 1 \\
\hline Monegros to be a tranquil place with a high quality of life with people & 3 & 1 \\
\hline Planning development by geographical zones & 1 & 1 \\
\hline Fostering grass-roots awareness and education; teaching children to appreciate what is local & 1 & 1 \\
\hline Business training for the people of Monegros & 1 & 1 \\
\hline Active resistance to the nuclear waste dump & 1 & 1 \\
\hline Rationalizing the transformation in irrigation. Sharing out green areas so all municipalities have access & 1 & 1 \\
\hline Public transport & 1 & 1 \\
\hline Integrated training of people to be oneself & 1 & 1 \\
\hline Tourism, impulse to agritourism (getting people involved, creating routes, festivals and cultural fairs) & - & 0 \\
\hline Services for the inhabitants of Monegros themselves (nursery, English classes, etc.), making the area strong & - & 0 \\
\hline Creation of forums with real, effective participation in the service of the local people and outside politics & - & 0 \\
\hline Legislating within a rural and not an urbanite context & - & 0 \\
\hline Making woollen eiderdowns & - & 0 \\
\hline Supporting family-run businesses & - & 0 \\
\hline Renewable and alternative energies, bioenergy and energy crops & - & 0 \\
\hline Return of well-trained and qualified human capital, grey matter, by means of self-employment & - & 0 \\
\hline Rewards for the function of guardians of the environment & - & 0 \\
\hline Plan for boosting the trade service sector & - & 0 \\
\hline Proper exploitation of potential for hunting with sufficient pay & - & 0 \\
\hline
\end{tabular}


Table 2: Continue

\begin{tabular}{|c|c|c|}
\hline Items & Points & Votes \\
\hline Model pilot projects with private involvement, though with initial public backing & - & 0 \\
\hline Responsible tourism (scientific, quality congresses, seminars), active, dynamic, learning about the environment, & - & 0 \\
\hline making use of the area's uniqueness: omithology, star-gazing, plants & - & - \\
\hline Solving the problem of purines & - & 0 \\
\hline Opportunity for immigration: how much? how? (accepting it, integrating it) & - & 0 \\
\hline Creating a brand of quality associated with the area & - & 0 \\
\hline That the civil servants, educators and health workers should live in the area & - & 0 \\
\hline Protecting the territory from multinationals, curbing the over-exploitation in pig-farming & - & 0 \\
\hline That the important role of women in Monegros is given due recognition, especially by men & - & 0 \\
\hline Fostering the creation of abattoirs with institutional help, to promote the transformation of pig-farming & - & 0 \\
\hline Involvement of local public bodies with the promoters of economic initiatives & - & 0 \\
\hline Ascription to Agenda 21 & - & 0 \\
\hline Urban planning without losing the historic old part of villages & - & 0 \\
\hline Proper management of straw ricks, purines, farmhouses so that they have value & - & 0 \\
\hline Promotion of ecological agriculture & - & 0 \\
\hline Assessment of wind and solar energy & - & 0 \\
\hline Management of pollutant waste (containers, treatment) & ـ & 0 \\
\hline
\end{tabular}

Table 3: Ideas for the development of monegros obtained in focal group 3 (specialists and public office-holders)

Items

Promoting the employment of women

Restructuring the entire agricultural and livestock production system

Importance attached to the uniqueness of the area

Trying to get used to the idea of the value of citizens' associations

Improvements in roads and communications

Diverse future, not only agriculture and livestock farming

Creating agro-food industries

Creation of telecentres and telework (31)

Star products: FEMOGA, ESTEPAREA, CARTUJA 2007 (fairs and expositions)

Social irrigation in Monegros Secos (areas $<2500$ ha)

The people of Monegros convincing themselves that the area has possibilities**

Modernization of irrigation in the area of Flumen

Appreciation of local products

Definitive boost to quality sheep-farming (extensive and fenced dry farming) (14)

Producing more quality than quantity

Ad hoc training (according to the needs of each individual) for the population

Maintaining the area's heritage, preserving traditions and using local knowledge

Fostering ecological production

Involvement of the administration in providing information about the area

Small industrial estates in villages for transformation

Promoting the joint use of the land

Recovering former crops (pulses) with high outward value

Integrated agriculture and livestock enterprises

Fostering ornithological and ecological tourism

Creation of businesses that transform and market the area

Hunting to be valued, commercial hunting activities

Extensive cattle farming over irrigation

Integrating the primary sector (pig farming) and the tertiary sector (livestock tourism)

The progress of Monegros should not entail the retrogression of other areas (theme of water)

Leisure centres (e.g., Tardienta) as support for rural tourism

Promoting alfalfa as an ecological crop

Participation of the population in development

Improvement on current cooperativism

Use of imagination to discover possibilities

Acceptance of the area's environmental and legal limiting factors

That people from outside the Monegros should get to know Monegros and its inhabitants

Promotion of self-employment among young people

Making economic use of the subsoil (e.g., geothermal resources)

Diversity of activities

Baby sitting facilities

Employment workshops/workshop schools

Centres of interpretation of nature

Nurseries in the larger villages

Generation of wealth and creation of services

Creation of a mixed public-private company for producing high-quality rice

Drawing public attention also to the current heritage of the area, the present way of life (e.g.,

Points Vote

$12 \quad 5$

the significance of Riegos del Altoaragon, the community of irrigation systems of the Aragonese highlands)

People required (as social technicians), to get things moving socially

The water saved by modernizing the irrigation sy stem should become part of the whole system,

forming part of a water bank in the general system

Recovery of crafts such as shepherd, carpenter or bricklayer, for which there is demand that cannot be met

14

4

0


perception of irrigation as a development option diminishes in importance, indeed to a minimum, to the extent that we approach the local population and the main actors involved in the decision-making process.

We consider that what is relevant about this work with focal groups on the development of Monegros is the light it sheds on a new and powerful perception that is emerging among the population of Monegros and certain people involved in decision-making: the integrated development of Monegros uncoupled from irrigation and linked to the idea of the territory's sustainability.

\section{CONCLUSION}

Analysis of the final discussions of the focal groups seems to indicate that such a perception is associated with an awareness of a different relationship with society and the environment, an awareness of forming part of a complex world that is changing at a dizzying pace and where a multitude of interactions on all levels end up affecting the local level, a world whose natural, cultural and social heritage have become key aspects of development. This consciousness can be identified with that postulated by Maturana and Varela (1987) in their biology of knowledge, a consciousness that can be stimulated through dialogue and participation with authentic social relations in decision-making processes.

\section{RECOMMENDATIONS}

It is suggested that public institutions in any territory should take into account participation and social dialogue in decision-making processes that seek to contribute to sustainability.

\section{REFERENCES}

Berkhout, F. and J. Hertin, 2002. Foresight futures scenarios: Developing and applying a participative strategic planning tool. Greener Manage. Int., 37: $37-52$.

De Vries, B.J.M. and A.C. Petersen, 2009. Conceptualizing sustainable development: An assessment methodology connecting values, knowledge, worldviews and scenarios. Ecol. Econ., 68: 1006-1019.
Delbecq, A.L., A.H. Van de Ven and D.H. Gustafson, 1975. Group Techniques for Program Planning: A Guide to Nominal Group and Delphi Processes. Scott, Foresman, Glenview, IL., USA., ISBN-13: 9780673075918, pp: 174..

Eames, M. and J. Skea, 2003. The development and use of the UK environmental futures scenarios: Perspectives from cultural theory. Greener Manage. Int., 37: 53-70.

Karakosta, C., A. Flamos and H. Doukas, 2010. Sustainable energy technology transfers through the CDM? Application of participatory approaches for decision making facilitation. Int. J. Environ. Policy Decis. Making, 1: 1-16.

Maturana, H. and F. Varela, 1987. The Tree of Knowledge: The Biological Roots of Human Understanding. Shambhala Press, Boston, MA., USA., ISBN-13: 9780877733737, pp: 263

Munda, G., 1997. Environmental economics, ecological economics and the concept of sustainable development. Environ. Values, 6: 213-233.

Munda, G., 2004. Social multi-criteria evaluation: Methodological foundations and operational consequences. Eur. J. Oper. Res., 158: 662-677.

Raskin, P., B. Tariq, G. Gallopin, P. Gutman, A. Hammond, R. Kates and R. Swart, 2002. Great transition: The Promise and Lure of the Times Ahead. Stockholm Environment Institute, Stockholm, Sweden, ISBN-13: 978-0971241817, pp: 99.

Rist, S., 2004. Endogenous development as a social learning process. COMPAS Magazine, Sept. 26-29. http://www.compasnet.org/afbeeldingen/Magazine s/CM7/cm7_09.pdf.

Rist, S., F. Delgado and U. Wiesmann, 2003. The role of social learning processes in the emergence and development of Aymara land use systems. Mt. Res. Dev., 23: 263-270.

Thompson, M., R.J. Ellis and A.B. Wildavsky, 1990. Cultural Theory. Westview Press, Boulder, CO., USA., ISBN-13: 9780813378633 , pp: 296.

Van Asselt, M.B.A. and J. Rotmans, 2002. Uncertainty in integrated assessment modelling. Clim. Change, 54: 75-105.

Van Asselt, M.B.A., 2000. Perspectives on Uncertainty and Risk: The PRIMA Approach to Decision Support. Kluwer Academic Press, Dordrecht, The Netherlands, ISBN-13: 9780792366560 , pp: 434. 